\title{
CLIMATE CHANGE AND AGRICULTURE RESEARCH PAPER Predicting global geographical distribution of Lolium rigidum (rigid ryegrass) under climate change
}

\author{
E. CASTELLANOS-FRÍAS ${ }^{1}$, D. GARCIA DE LEÓN ${ }^{1,2}$, F. BASTIDA ${ }^{3}$ AND \\ J. L. GONZALEZ-ANDUJAR ${ }^{1,2 *}$ \\ ${ }^{1}$ Instituto de Agricultura Sostenible (CSIC), Aptdo. 4084, 14080 Córdoba, Spain \\ ${ }^{2}$ Laboratorio Internacional en Cambio Global, LINCGlobal (CSIC-PUC), Santiago, Chile \\ ${ }^{3}$ Departamento de Ciencias Agroforestales, Universidad de Huelva, Campus La Rábida, Ctra. Palos s/n, 21819 Palos de la \\ Frontera, Huelva, Spain
}

(Received 14 January 2015; revised 19 June 2015; accepted 21 July 2015;

first published online 5 November 2015)

\section{SUMMARY}

Lolium rigidum L. (rigid ryegrass) is one of the most extensive and harmful weeds in winter cereal crops. A bioclimatic model for this species was developed using CLIMEX. The model was validated with records from North America and Oceania and used to assess the global potential distribution of L. rigidum under the current climate and under two climate change scenarios. Both scenarios represent contrasting temporal patterns of economic development and carbon dioxide $\left(\mathrm{CO}_{2}\right)$ emissions. The projections under current climatic conditions indicated that L. rigidum does not occupy the full extent of the climatically suitable area available to it. Under future climate scenarios, the suitable potential area increases by $3 \cdot 79 \%$ in the low-emission $\mathrm{CO}_{2}$ scenario and by $5 \cdot 06 \%$ under the most extreme scenario. The model's projection showed an increase in potentially suitable areas in North America, Europe, South America and Asia; while in Africa and Oceania it indicated regression. These results provide the necessary knowledge for identifying and highlighting the potential invasion risk areas and for establishing the grounds on which to base the planning and management measures required.

\section{INTRODUCTION}

Global climate change is one of the greatest threats to the sustainability of ecosystems (Bellard et al. 2012) with multiple consequences from a reduction in biodiversity to irreversible soil erosion of land (Perarnaud et al. 2005). Therefore, there will be important alterations in agrosystems, in which some predictions indicate a reduction of around $10-20 \%$ in crop production (IPCC 2007). Weed flora would be especially affected, both negatively and positively, with alterations in the competitive interactions between weeds and crops (Gonzalez-Andujar 1995; Ziska et al. 2011) and in the geographic distributions of weeds (Walck et al. 2011; Bourdôt et al. 2013). Estimating weed species' climate matches under projected climate change is a priority to predict future climatically suitable areas for species occupation. Recently, process-based niche models such as

* To whom all correspondence should be addressed. Email: andujar@cica.es
CLIMEX have been widely used to project the potential geographic distribution of plants under current and future climate change scenarios (Chejara et al. 2010; Kriticos et al. 2010; Clements \& Ditommaso 2011; Castellanos-Frías et al. 2014).

Lolium rigidum Gaud. is one of the most widespread and harmful grass weeds in winter cereal crops in Mediterranean environments (Monaghan 1980; Recasens et al. 1997; Steadman et al. 2004). Its origin is located in the Middle East (Recasens et al. 1997) and from there it spread throughout the Mediterranean. Later, it was introduced or spread to North and South America, South Africa and Australia. The biology of L. rigidum in these cropping systems is characterized by high germination rates from the soil seedbank and high adult fertility, with low natural mortality of seedlings and adults (Recasens et al. 1997; Taberner 2001), which favours high population densities of this weed in the absence of control measures. The consequences of heavy infestations of rigid ryegrass on winter cereal 
crops can significantly affect the profitability of the crop, with yield losses of up to $83 \%$ seen in barley when densities reached 1240 plants $/ \mathrm{m}^{2}$ in central Spain (Izquierdo et al. 2003). In Australia, densities of 300 plants $/ \mathrm{m}^{2}$ produced 42 and $55 \%$ losses in wheat and barley, respectively (Lemerle et al. 1995).

The emergence of $L$. rigidum is highly dependent on temperature and rainfall (Izquierdo et al. 2013). Therefore, it is highly likely that $L$. rigidum might be affected by climate change with a resulting modification of its current geographic distribution. Despite the large economic losses that $L$. rigidum can cause in cereal crops, there is no information about the geographic range over which this species could potentially spread under the current and future climate change scenarios. Information describing this range would offer considerable insight into the areas vulnerable to the invasion of this weed, allowing farmers to prioritize control programmes. In the present study a process-based niche model was developed and used to (i) estimate the current global potential distribution of $L$. rigidum and (ii) predict the potentially global suitable area under future climate scenarios. Ultimately the current work should help prioritize management efforts against $L$. rigidum by identifying locations that might be suitable for this species.

\section{MATERIAL AND METHODS}

The software program CLIMEX (Hearne Scientific Software, Sutherst et al. 2007) was used to develop the bioclimatic niche model for L. rigidum. It is a dynamical model that provides a measure of potential distribution based on the climatic requirements of a species. It uses various growth- and stress-related indices to describe the potential of population growth under favourable and unfavourable conditions. The growth and stress indices combine to provide the ecoclimatic index (EI), which gives an overall estimate of the suitability of a given location for the species in question (Sutherst et al. 2007). It ranges from 0 to 100, where $0=$ area not suitable for species persistence and $100=$ area wholly suitable for persistence. In the present study, El was divided into four classes of suitability for species growth for further analysis: 0, unsuitable; 1-10, marginal; 10-20, suitable; and >20, optimal (Sutherst \& Maywald 2005; Sutherst et al. 2007). The El data generated by CLIMEX were interpolated using the inverse distance weighted method, and represented in ArcGIS 10 to quantify suitable areas. The resulting grid cells were then reclassified according to the three El classes and the total area in each class was determined. The current global distribution was derived from the literature and various databases (Terrell 1968; Cocks \& Donald 1973; Gramshaw 1976; Tutin et al. 1980; Recasens et al. 1997; Fernández-Quintanilla et al. 2000; Chen et al. 2006; Kirkby et al. 2011; EUROMED 2014; CABI 2014; GBIF 2014; Missouri Botanical Garden 2014; USDA 2014; CHAH 2014) (Supplementary Material: go to http://journals.cambridge.org/AGS).

Parameter values were obtained mainly from the literature and, when necessary, were calibrated iteratively based on the current distribution of ryegrass in Europe (Sutherst et al. 2007; Kriticos et al. 2010). Lower optimal temperature (DV1) and upper optimal temperature (DV2) were obtained from seed germination and seedling emergence studies (Recasens et al. 1997; Taberner 2001; Izquierdo et al. 2013) and were set at 7.4 and $30^{\circ} \mathrm{C}$, respectively (Table 1). The lower temperature threshold (DV0) and the limiting high temperature (DV3) were defined from minimum and maximum temperatures recorded in the area where the species is currently distributed (Recasens et al. 1997; Taberner 2001) (Table 1). The heat stress temperature threshold (TTHS) was established at $35^{\circ} \mathrm{C}$ because it was reported that $L$. rigidum is able to persist up to this temperature in Spain (Recasens et al. 1997; Taberner 2001) with an accumulation rate (THHS) of 0.00001/ week (Table 1). Moisture indices and dry stress were established iteratively based on geographic distribution records for the species (Table 1). The cold stress threshold (TTCS) and accumulation rate (THCS) were set at $0{ }^{\circ} \mathrm{C}$ and $0 \cdot 0015 /$ week, respectively, because the plant is susceptible to frost damage. These parameters were adjusted iteratively to allow it to barely persist in some areas of northern Spain where the minimum winter temperature regularly goes well below $0{ }^{\circ} \mathrm{C}$ (Table 1$)$. The parameters degree-days threshold (DTCS) and the cold stress accumulation rate (DHCS) (Table 1) evaluate whether thermal accumulation is enough to explain the presence of this species. As shown by Kriticos et al. (2010) and McConnachie et al. (2011) in their studies with weeds, it is advisable to include these indices in order to obtain a better fit of the geographic distribution, otherwise the presence of L. rigidum in Northern Europe and North America would be overestimated.

Lolium rigidum is well suited to Mediterranean conditions (Recasens et al. 1997), where the moisture level is low and, thus, a wet excess could be negative 
Table 1. Parameters used in the CLIMEX model for L. rigidum

\begin{tabular}{|c|c|c|c|}
\hline \multirow{2}{*}{$\frac{\text { Index }}{\text { Temperature }}$} & \multicolumn{2}{|c|}{ Parameter } & \multirow{2}{*}{$\frac{\text { Value }}{1 \cdot 8^{\circ} \mathrm{C}}$} \\
\hline & DV0 & Lower temperature threshold & \\
\hline & DV1 & Lower optimum temperature & $7 \cdot 4^{\circ} \mathrm{C}$ \\
\hline & DV2 & Upper optimum temperature & $30^{\circ} \mathrm{C}$ \\
\hline & DV3 & Upper temperature threshold & $35{ }^{\circ} \mathrm{C}$ \\
\hline \multirow[t]{4}{*}{ Moisture } & SMO & Lower soil moisture threshold & $0 \cdot 24 *$ \\
\hline & SM1 & Lower optimal soil moisture & $0 \cdot 3^{*}$ \\
\hline & SM2 & Upper optimal soil moisture & $1^{*}$ \\
\hline & SM3 & Upper soil moisture threshold & $1 \cdot 4^{*}$ \\
\hline \multirow[t]{4}{*}{ Cold stress } & TTCS & Cold stress temperature threshold & $0{ }^{\circ} \mathrm{C}$ \\
\hline & THCS & Cold stress accumulation rate & -0.0015/week \\
\hline & DTCS & Degree-days threshold & 13 degree-days \\
\hline & DHCS & Cold stress accumulation rate & $-0 \cdot 00004 /$ week \\
\hline \multirow[t]{2}{*}{ Heat stress } & TTHS & Heat stress temperature threshold & $35^{\circ} \mathrm{C}$ \\
\hline & THHS & Heat stress accumulation rate & 0.00001/week \\
\hline \multirow{2}{*}{ Dry stress } & SMDS & Soil moisture dry stress threshold & $0 \cdot 01^{*}$ \\
\hline & HDS & Dry stress accumulation rate & $-0 \cdot 006 /$ week \\
\hline \multirow[t]{2}{*}{ Wet stress } & SMWS & Soil moisture wet stress threshold & $1 \cdot 4^{*}$ \\
\hline & HWS & Wet stress accumulation rate & 0·001/week \\
\hline \multirow[t]{3}{*}{ Hot-wet stress } & TTHW & Temperature threshold & $24{ }^{\circ} \mathrm{C}$ \\
\hline & MTHW & Hot-wet moisture threshold & $0 \cdot 3^{*}$ \\
\hline & PHW & Hot-wet stress accumulation rate & 0·099/week \\
\hline $\begin{array}{l}\text { Thermal } \\
\text { accumulation }\end{array}$ & PDD & $\begin{array}{l}\text { Number of degree-days above DV0 necessary to complete one } \\
\text { generation }\end{array}$ & $\begin{array}{l}2032 \text { degree- } \\
\text { days }\end{array}$ \\
\hline \multirow[t]{5}{*}{ Dormancy } & DPD0 & Dormancy induction daylength & $13 \cdot 9 \mathrm{~h}$ \\
\hline & DPT0 & Dormancy induction temperature & $12{ }^{\circ} \mathrm{C}$ \\
\hline & DPT1 & Dormancy termination temperature & $20^{\circ} \mathrm{C}$ \\
\hline & DPD & Dormancy development days & 120 days \\
\hline & DPSW & Dormancy summer indicator & $1^{*}$ \\
\hline
\end{tabular}

* Dimensionless value.

for this species. The wet stress threshold (SMWS) was set at 1.4 and the accumulation rate (HWS) was adjusted to 0.001/week (Table 1) (Sutherst et al. 2007) in order to prevent $L$. rigidum from growing in very wet locations.

The hot-wet stress index is recommended to separate Mediterranean species from tropical ones. It was defined according to Sutherst et al. (2007) and finetuned with the results of the model. The temperature threshold for hot-wet stress (TTHW) was set at $24{ }^{\circ} \mathrm{C}$, with a moisture threshold (MTHW) of 0.3 and a stress accumulation rate (PHW) of 0.099/week.

Geographic distribution of species is also determined by the thermal accumulation required to reach a minimum amount of development to complete the life-cycle (Sutherst et al. 2007; Kriticos et al. 2010). Thermal accumulation (PDD) was collected from the literature (Recasens et al. 1997) and set at 2032 degree-days (Table 1).

The Dormancy induction day length (DPD0) was taken from Sutherst et al. (2007) for Mediterranean areas. Seed dormancy induction temperature (DPT0) and seed dormancy termination temperature (DPT1) were iteratively calibrated.

The minimum number of days necessary to terminate seed dormancy (DPD) was set at 120 days (Table 1) based on the literature on the life-cycle of L. rigidum, reporting seed dormancy between June and October (Recasens et al. 1997; Taberner 2001).

Model validation

The model was validated with records from North America and Oceania (Sutherst \& Maywald 2005). A 
Table 2. Climate change scenarios in the world by the year 2100

\begin{tabular}{llllll}
\hline \hline $\begin{array}{l}\text { Emissions } \\
\text { scenario }\end{array}$ & Global population (billion) & $\mathrm{CO}_{2}$ concentration $(\mathrm{ppm})$ & Global $\Delta T\left({ }^{\circ} \mathrm{C}\right)$ & Likely range $\left({ }^{\circ} \mathrm{C}\right)$ \\
\hline \multirow{2}{2}{2100} & $\mathrm{~A} 1 \mathrm{~B}$ & $7 \cdot 1$ & 711 & $2 \cdot 9$ & $1 \cdot 7-4 \cdot 4$ \\
& $\mathrm{~A} 2$ & $15 \cdot 1$ & 857 & $3 \cdot 8$ & $2 \cdot 0-5 \cdot 4$ \\
\hline \hline
\end{tabular}

Source: IPCC (2007).

quantitative assessment of the agreement between known and predicted distribution of L. rigidum was made through the calculation of the area under the curve $(A \cup C)$ of the receiver operating characteristic (ROC). The ROC curve is obtained by plotting the species' true positive (correspondence between real presence and simulated data) rate and the false positive (no correspondence between real presence and simulated data) rate and describes the compromise that a model attains between including known presences and excluding absences. The AUC provides an objective measure of accuracy (Elith et al. 2006), varying from 0.5 for randomness to 1.0 for a perfect fit. This $A \cup C$ is commonly applied in the assessment of the accuracy of species distribution models (Ni et al. 2012).

\section{Meteorological database}

The climate database was taken from the CliMond website (Kriticos et al. 2012) as it provides the variables required by CLIMEX. The historical meteorological data are centred on the year 1975, representing the reference period 1961-90. These data consist of a global 30' regular grid with 67419 points distributed over the land worldwide, corresponding to approximately $50 \times 50 \mathrm{~km}$ of resolution. The climate database was included in the rigid ryegrass model to infer its climate requirements, and thus to establish its geographic distribution.

\section{Climate change scenarios}

The effect of climate change on the potential global distribution of $L$. rigidum was assessed through the CSIRO-MK3 (CSIRO, Australia) global climate model (GCM). This model represents the climate at a regional scale relatively well, and provides the data required by CLIMEX (Kriticos et al. 2012). The target year was set at 2100 using different greenhouse gas emission scenarios. The GCM was subjected to the conditions of medium (A1B) and high (A2) emission scenarios (IPCC 2007; Rahmstorf et al. 2007) (Table 2). These two scenarios include contrasting temporal patterns of economic development and carbon dioxide $\left(\mathrm{CO}_{2}\right)$ emissions. The A2 scenario describes a world with a great regional inequality based on a continuous increase in global population, economic growth and technological change, fragmented and medium-high $\mathrm{CO}_{2}$ emissions. The A1B scenario contemplates a rapid economic growth with a maximum value of global population in mid-century, declining thereafter, and a rapid and more efficient introduction of new technologies based on a balanced use across all sources of energy (Table 2).

\section{RESULTS}

Validation analysis shows a good agreement with the known distribution of $L$. rigidum in North America $(A \cup C=0.98)$ and Oceania ( $A \cup C=0.96)$. Any $A \cup C$ values $>0.75$ are indicative of high prediction accuracy and $>0.9$ models are considered to be excellent (Elith et al. 2006). These results reveal a good model performance for predicting with high accuracy the geographic distribution of L. rigidum.

Potential distribution under the current climate

Model prediction of the current global geographic distribution of $L$. rigidum corresponded well to their known distribution (Fig. 1). The AUC value of 0.97 indicates that the model has great discrimination ability. The current potential global distribution of ryegrass was estimated at $7.9 \times 10^{6} \mathrm{~km}^{2}$, of which $47 \%$ $\left(3.7 \times 10^{6} \mathrm{~km}^{2}\right)$ are optimal locations, $19 \%(1.5 \times$ $\left.10^{6} \mathrm{~km}^{2}\right)$, are suitable ones and $34 \%\left(2 \cdot 7 \times 10^{6} \mathrm{~km}^{2}\right)$ are marginal locations (Table 3 ). The optimal areas were located mainly in Mediterranean climate areas (Fig. 1). Europe and Oceania have the largest suitable areas with $22 \%$ and $16 \%$ of their territory, respectively (Fig. 1). In Europe, the territory appropriate for L. rigidum is almost continuous, covering $2.19 \times 10^{6}$ $\mathrm{km}^{2}$ and including the Mediterranean countries, central Europe, low altitude regions of northern Europe, and also a small area in the southeast (Fig. 1; 


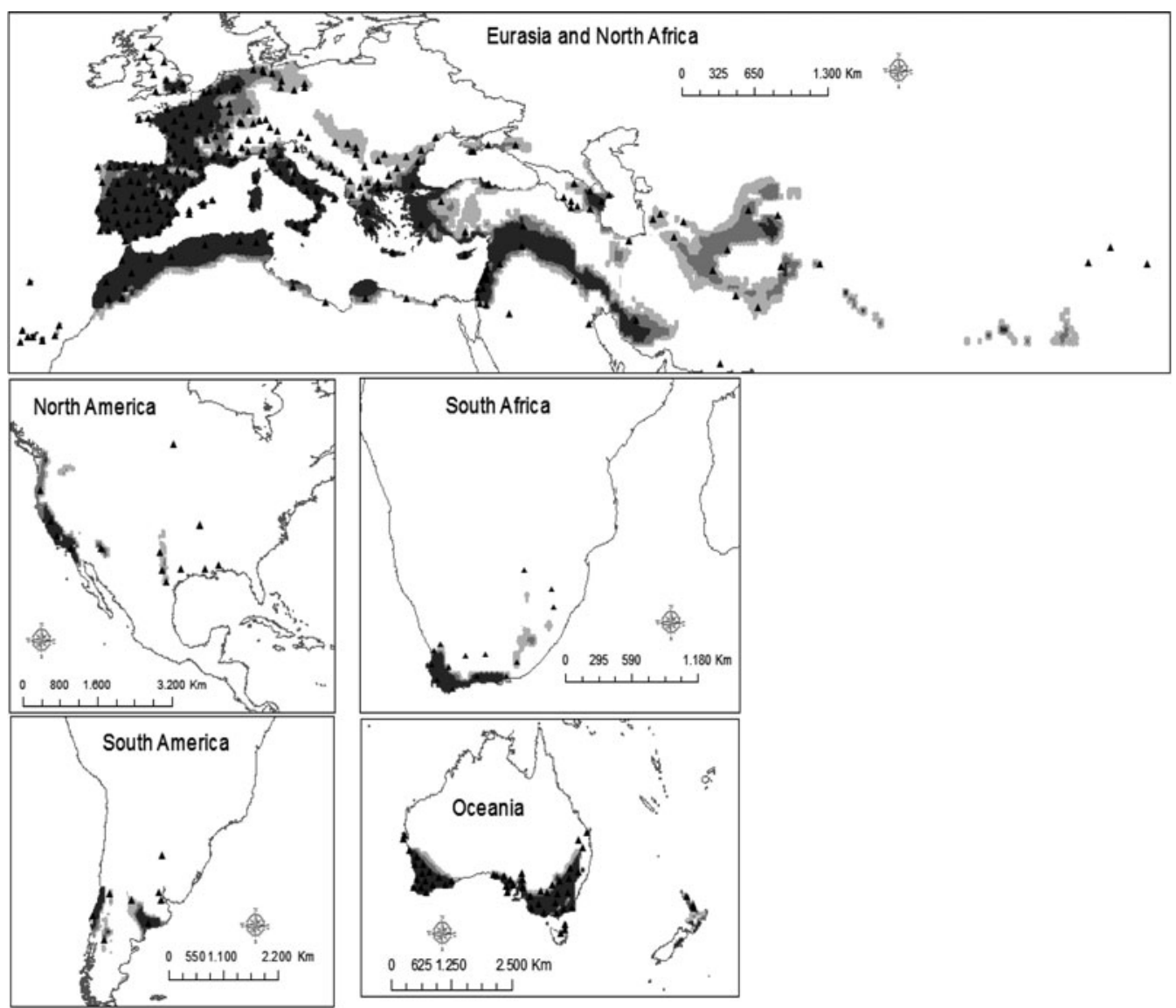

Fig. 1. Current projected global geographical distribution of L. rigidum according to the El using CLIMEX model: $\square$ unsuitable; $\square$ marginal; $\square$ suitable and $\square$ optimal. Known distribution of L. rigidum (triangles). Field occurrences were obtained from published records and databases.

Table 4). The area of potential distribution of ryegrass in Oceania reaches $1.39 \times 10^{6} \mathrm{~km}^{2}$, much of southern Australia and northern New Zealand (Fig. 1; Table 4). In North America, the most suitable areas $(0.61 \times$ $10^{6} \mathrm{~km}^{2}$ ) are concentrated on the West Coast, in Mediterranean-type environments (Fig. 1; Table 4), while in South America, distribution $\left(0.46 \times 10^{6} \mathrm{~km}^{2}\right)$ affects Chile and Argentina (Fig. 1; Table 4). The distribution in Africa $\left(0.88 \times 10^{6} \mathrm{~km}^{2}\right.$; Fig. 1 ; Table 4) fitted the existing records for the north of the continent very well (a narrow strip along the Mediterranean basin), and in South Africa (Fig. 1). In Asia, ryegrass can potentially infest $2.37 \times 10^{6} \mathrm{~km}^{2}$, affecting countries adjacent to the Mediterranean sea, the Black and Caspian seas and central latitudes of the continent (Fig. 1; Table 4).

Future geographic distribution under climate change Under future climate change scenarios, areas climatically suitable to L. rigidum are projected to increase globally, by up to $3 \cdot 79$ and $5 \cdot 06 \%$ of the earth's land surface under both the low-carbon emission scenario (A1B) and the most extreme scenario (A2), respectively (Table 3; Figs 2 and 3). Nevertheless, the optimal areas for the weed species are potentially reduced by $16 \cdot 2 \%$ (A1B) and $10 \cdot 8 \%$ (A2). In contrast, suitable and marginal distribution areas show a sharp increase. The suitable areas increase by $26.7 \%$ under both $\mathrm{A} 1 \mathrm{~B}$ and $\mathrm{A} 2$ scenarios, whereas marginal areas experience a potential increase of 18.5 and $14.8 \%$ under A1B and A2 scenarios, respectively (Table 3; Figs 2 and 3 ).

Europe, Asia, North and South America show a potential increase in suitable areas for rigid ryegrass, indicating considerable scope for further invasion of $L$. rigidum. The most pronounced expansion of this weed might happen in North America and Europe. In North America, an increment of 109.7 and $175.6 \%$ in distribution area is projected under A1B and A2 scenarios, respectively (Table 4; Figs 2 and 3), 
Table 3. Projected land area climatically suitable ( $E I \geq 1)$ for L. rigidum under current climate, expressed as an area and as a percentage of increment/decrement on total infested land area under climate change scenarios (A1B and A2) for 2100

\begin{tabular}{|c|c|c|c|c|c|c|c|c|}
\hline & \multicolumn{2}{|c|}{ Total } & \multicolumn{2}{|c|}{ Marginal } & \multicolumn{2}{|c|}{ Suitable } & \multicolumn{2}{|c|}{ Optimal } \\
\hline & Area $\left(\mathrm{km}^{2}\right)$ & $\%$ & Area $\left(\mathrm{km}^{2}\right)$ & $\%$ & Area $\left(\mathrm{km}^{2}\right)$ & $\%$ & Area $\left(\mathrm{km}^{2}\right)$ & $\%$ \\
\hline Current climate & $7.9 \times 10^{6}$ & & $2 \cdot 7 \times 10^{6}$ & & $1.5 \times 10^{6}$ & & $3.7 \times 10^{6}$ & \\
\hline CSIRO A1B & $8 \cdot 2 \times 10^{6}$ & $3 \cdot 79$ & $3 \cdot 2 \times 10^{6}$ & $18 \cdot 51$ & $1.9 \times 10^{6}$ & $26 \cdot 66$ & $3 \cdot 1 \times 10^{6}$ & $-16 \cdot 21$ \\
\hline CSIRO A2 & $8 \cdot 3 \times 10^{6}$ & $5 \cdot 06$ & $3 \cdot 1 \times 10^{6}$ & 14.81 & $1.9 \times 10^{6}$ & $26 \cdot 66$ & $3 \cdot 3 \times 10^{6}$ & $-10 \cdot 81$ \\
\hline
\end{tabular}

Table 4. Percentage change, by continent, of the potential distribution of $\mathrm{L}$. rigidum under climate change ( $A 1 B$ and A2), with respect to the current surface

\begin{tabular}{lcccccc}
\hline \hline & Africa & Asia & Europe & North America & Oceania & South America \\
\hline Current $\left(\times 10^{6} \mathrm{~km}^{2}\right)$ & $0 \cdot 88$ & $2 \cdot 37$ & $2 \cdot 19$ & $0 \cdot 61$ & $1 \cdot 39$ & $0 \cdot 46$ \\
CSIRO A1B $(\%)$ & $-46 \cdot 1$ & $17 \cdot 5$ & $108 \cdot 7$ & $109 \cdot 7$ & $-48 \cdot 0$ & $20 \cdot 8$ \\
CSIRO A2 $(\%)$ & $-66 \cdot 8$ & $22 \cdot 3$ & $167 \cdot 3$ & $175 \cdot 6$ & $-59 \cdot 5$ & $17 \cdot 9$ \\
\hline \hline
\end{tabular}

mainly concentrated in coastal areas of western United States and Canada and central areas of the USA (Figs 2 and 3). Suitable areas are also projected to increase substantially in Europe, by 108.7 and $167 \cdot 3 \%$ under $\mathrm{A} 1 \mathrm{~B}$ and $\mathrm{A} 2$ scenarios, respectively (Table 4; Figs 2 and 3), with suitable territories shifting towards northern (Ireland, Denmark, Sweden or Norway) and eastern countries (Latvia, Estonia, Moldova, Ukraine or Russia) (Figs 2 and 3). Minor increments in distribution areas are projected for South America and Asia (Figs 2 and 3; Table 4). Africa and Oceania presented a marked reduction under the two climate change scenarios (Table 4; Figs 2 and 3).

\section{DISCUSSION}

The ultimate value of the results is subject to the validity of the model, which is supported by a high degree of congruence between known distribution and predicted geographic distribution and the high AUC values.

The present results clearly suggest that, under the current climate, this weed species is capable of occupying a greater range globally than it covers at present. Continents with the most potential for expanding in its native range are Europe, Asia, North America and South America.

Under future climate conditions the potential geographic distribution of $L$. rigidum may change following a poleward trend, occupying areas that are currently too cold for its survival. The potential area climatically suitable is projected to increase by $3.79 \%$ $\left(0.3 \times 10^{6} \mathrm{~km}^{2}\right)$ under the A1B scenario and by $5 \cdot 06 \%$ under scenario A2 $\left(0 \cdot 4 \times 10^{6} \mathrm{~km}^{2}\right)$. Both scenarios produced a similar available area for the growth of ryegrass.

The largest increases in infestation area, under both climate change scenarios, would happen in North America and Europe. In North America, the potential increment in distribution area could reach $175.6 \%$ $\left(1.67 \times 10^{6} \mathrm{~km}^{2}\right)$ under the worst-case scenario (A2). According to the potential distribution projected for rigid ryegrass, the US states mostly affected could be California, Oregon, Washington, Idaho, Montana, Nevada, Utah, Wyoming, Colorado, Nebraska, Kansas, Oklahoma, Texas and Michigan, all of which have important extensions of cereal crops (NASS-USDA 2014). Therefore, the potential spread of $L$. rigidum throughout these states may involve a significant impact in terms of crop yield losses.

In the same vein, Europe also shows a significant potential increase in the rigid ryegrass distribution area of $167 \cdot 3 \%$ under the worst-case scenario (A2). The general trend of $L$. rigidum is a north-eastern movement. Regions with the highest potential for invasion are located in the centre of the continent, the northern regions (Ireland, north of the UK and the Scandinavian countries) and the eastern countries (Ukraine and Russia). 


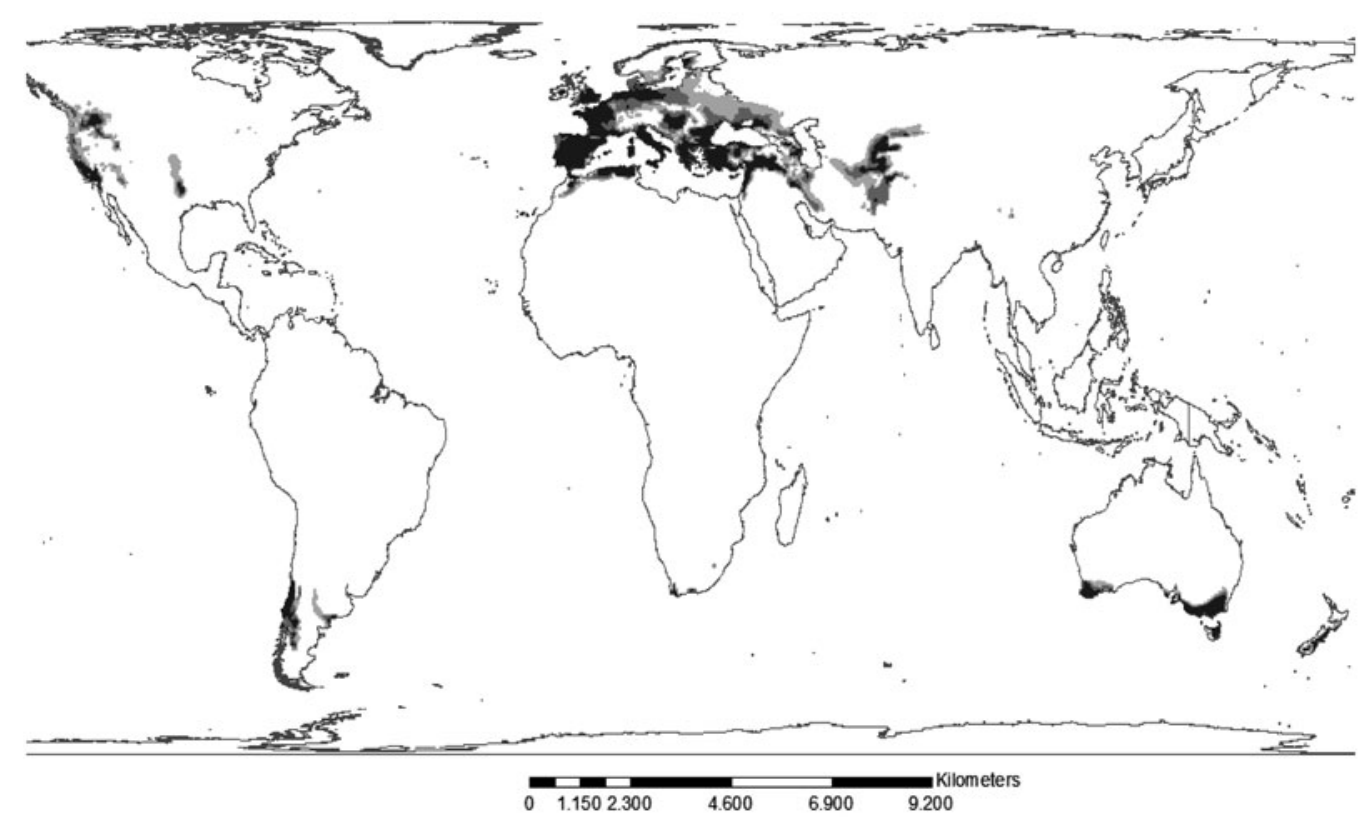

Fig. 2. The potential global geographical distribution of L. rigidum under climate change scenario CSIRO A1B projected for 2100, based on the El using CLIMEX model: $\square$ unsuitable; $\square$ marginal; $\square$ suitable and $\square$ optimal.

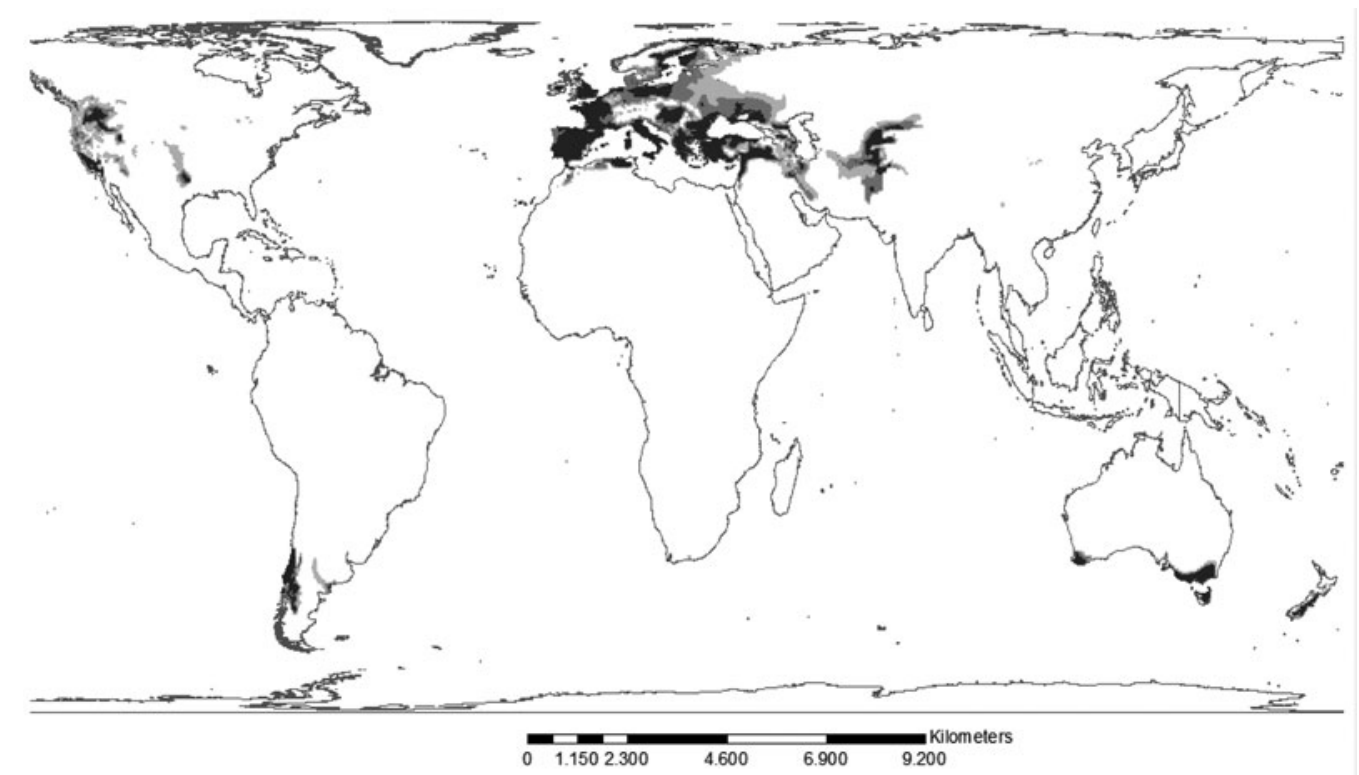

Fig. 3. The potential global geographical distribution of L. rigidum under climate change scenario CSIRO A2 projected for 2100, based on the El using CLIMEX model: $\square$ unsuitable; $\square$ marginal; $\square$ suitable and $\square$ optimal.

In South America and Asia, the model's results show the same trend of displacement towards the poles described for Europe or North America. The increasing area of L. rigidum over Asia poses a potential risk for countries like Turkey, Kazakhstan, Pakistan, Iran or Uzbekistan, important producers of wheat globally (FAOSTAT 2014). Meanwhile, China and India infestation areas might be reduced.
Conversely, the climate change scenarios project a reduction of up to $66 \cdot 8 \%$ in the total suitable area for L. rigidum in Africa and Oceania.

In the present study, two contrasting scenarios have been analysed. Both scenarios project increases in the potential suitable area of ryegrass. However, the variation does not always appear to be significant, depending on which climate model is used (Table 3), 
Chemical control of this weed is currently the main viable option. However, herbicide resistance (Gill \& Holmes 1997) in L. rigidum has been detected globally (Heap 2014). The likely global expansion of L. rigidum throughout Europe and North America could lead to an expansion of herbicide-resistant populations in these territories and, conversely, a decrease in Australia where rigid ryegrass resistance to herbicides is currently a problem (Owen et al. 2014).

Knowledge of shifts in the geographic distribution of L. rigidum under climate change is essential for identifying and highlighting potential invasion areas. This is a prerequisite on which to base preventive planning and management measures. The spread rate at which a weed occupies its potential range is dependent on its dispersal ability. In assessing the potential of $L$. rigidum invasion at a regional scale, the major factor that determines L. rigidum seed dispersal is human action (Baker et al. 2000). Special emphasis should be given to controlling global commerce of crop seeds in order to ensure that seed lots are weed-free (Michael et al. 2010), since otherwise they may favour the spread of L. rigidum over new potentially suitable areas.

The model developed in the present study provides some measure of confidence in the direction of the expected changes in the global distribution of L. rigidum under climate change. However, if anthropogenic emissions of greenhouse gases can be significantly reduced and/or there are significant changes in agricultural policies (e.g. changes in the amount of land used for cereal cultivation), then the changes in the geographic range of L. rigidum may be substantially different from those projected under the scenarios analysed in the current paper.

In summary, the present study has developed global distribution maps that identify areas in which L. rigidum could extend its range and countries that are at risk of invasion based on their climatic suitability. It also provides an indication of the likely changes in its geographic distribution under climate change. As climate conditions become extreme, it is expected that this weed will substantially increase its range, posing a serious threat to the economic and environmental sustainability of winter cereal crops. Therefore, this model could prove useful for identifying and highlighting the potential invasion risk areas and for establishing the grounds on which to base the planning and management measures required.

This work has been funded by FEDER (European Regional Development Funds) and the Spanish
Ministry of Economy and Competitiveness funds (Projects AGL2012-33736). Suggestions and commentaries from one anonymous reviewer greatly improved the former version of this article.

\section{SUPPLEMENTARY MATERIAL}

The Supplementary Material for this paper can be found at: http://journals.cambridge.org/AGS

\section{REFERENCES}

Baker, R. H. A., Sansford, C. E., Jarvis, C. H., Cannon, R. J. C., MACLfoD, A. \& Walters, K. F. A. (2000). The role of climatic mapping in predicting the potential geographical distribution of non-indigenous pests under current and future climates. Agriculture, Ecosystems and Environment 82, 57-71.

Bellard, C., Bertelsmeier, C., Leadley, P., Thuiller, W. \& Courchamp, F. (2012). Impacts of climate change on the future of biodiversity. Ecology Letters 15, 365-377.

Bourdôt, G.W., Lamoureaux, S.L., Watt, M.S. \& KRITICOS, D. J. (2013). The potential global distribution of tall buttercup (Ranunculus acris ssp. acris): Opposing effects of irrigation and climate change. Weed Science 61, 230-238.

CABI Centre for Agricultural Bioscience International (2014). Plantwise Knowledge Bank. Delémont, Switzerland: Plantwise. Available online from: http://www.plantwise. org/KnowledgeBank/PWMap.aspx (accessed 21 July 2015).

Castellanos-Frías, E., Garcia De Leon, D., Pujadas-Salva, A., Dorado, J. \& Gonzalez-Andujar, J. L. (2014). Potential distribution of Avena sterilis L. in Europe under climate change. Annals of Applied Biology 165, 53-61.

CHAH (2014). Australia's Virtual Herbarium. Canberra: Council of Heads of Australasian Herbaria. Available online from: http://avh.chah.org.au (accessed 23 June 2015).

Chejara, V. K., Kriticos, D. J., Kristiansen, P., Sindel, B. M., Whalley, R. D. B. \& Nadolny, C. (2010). The current and future potential geographical distribution of Hyparrhenia hirta. Weed Research 50, 174-184.

Chen, S.-L., Lı, D.-Z., Zhu, G., Wu, Z., Lu, S.-L., LiU, L., WanG, Z.-P., Sun, B.-X., ZhU, S.-D., XIA, N., JiA, L.-Z., Guo, Z., Chen, W., Chen, X., YanG, G., Phillips, S. M., Stapleton, C., Soreng, R. J., Aiken, S. G., Tzvelev, N. N., Peterson, P.M., Renvoize, S. A., Olonova, M. V. \& Ammann, K. (2006). Poaceae. Flora of China Vol. 22, (Series Eds Z. G. Wu \& P. E. Raven), Beijing \& St Louis: Science Press \& Missouri Botanical Garden Press.

Clements, D. R. \& Ditommaso, A. (2011). Climate change and weed adaptation: can evolution of invasive plants lead to greater range expansion than forescasted? Weed Research 51, 227-240.

Cocks, P.S. \& Donald, C. M. (1973). The germination and establishment of two annual pasture grasses (Hordeum leporinum Link. and Lolium rigidum Gaud.). Australian Journal of Agricultural Research 24, 1-10. 
Elith, J., Graham, C.H., Anderson, R.P., Dudík, M., Ferrier, S., Guisan, A., Hijmans, R. J., Huettmann, F., LeathWick, J. R., LehmanN, A., LI, J., LohmanN, L. G., Loiselle, B. A., Manion, G., Moritz, C., Nakamura, M., Nakazawa, Y., Overton, J.M.M., Peterson, A.T., Phillips, S.J., Richardson, K., Scachetti-Pereira, R., Schapire, R. E., Soberón, J., Williams, S., Wisz, M.S. \& ZimMERMANN, N. E. (2006). Novel methods improve prediction of species' distributions from occurrence data. Ecography 29, 129-151.

EUROMED (2014). EuroMed PlantBase: The Information Resource for Euro-Mediterranean Plant Diversity. Berlin: EUROMED. Available online from: http://www.emplantbase.org/home.html (accessed 23 June 2015).

FAOSTAT (2014). FAOSTAT. Rome: FAO. Available online from: http://faostat.fao.org (accessed 23 June 2015).

Fernández-Quintanilla, C., Barroso, J., Recasens, J., Sans, X., Torner, C. \& Sanchez Del Arco, M.J. (2000). Demography of Lolium rigidum in winter barley crops: analysis of recruitment, survival and reproduction. Weed Research 40, 281-291.

GBIF (2014). Global Biodiversity Information Facility: Free and Open Access to Biodiversity Data. Copenhagen: GBIF. Available online from: http://www.gbif.org (accessed 23 June 2015).

Gill, G. S. \& Holmes, J. E. (1997). Efficacy of cultural control methods for combating herbicide-resistant Lolium rigidum. Pesticide Science 51, Sp Iss, 352-358.

Gonzalez-Andujar, J. L. (1995). Modelling the effects of climate change and climatic variability on crops at the site scale: effects on cereal weeds. In Climate Change and Agriculture in Europe: Assessment of Impacts and Adaptations (Eds P. A. Harrison, R. E. Butterfield \& T. E. Downing), pp. 280-285. Oxford, UK: University of Oxford.

Gramshaw, D. (1976). Temperature/light interactions and the effect of seed source on germination of annual ryegrass (Lolium rigidum Gaud.) seeds. Australian Journal of Agricultural Research 27, 779-786.

HeAp, I. (2014). International Survey of Herbicide Resistant Weeds. Online database available from www. weedscience.org (accessed 23 June 2015).

IPCC (2007). Summary for policymakers. In Climate Change 2007: The Physical Science Basis. Contribution of Working Group I to the Fourth Assessment Report of the Intergovernmental Panel on Climate Change (Eds S. Solomon, D. Qin, M. Manning, Z. Chen, M. Marquis, K. B. Averyt, M. Tignor \& H. L. Miller), pp. 1-18. Cambridge, UK: Cambridge University Press.

Izquierdo, J., Recasens, J., Fernández-Quintanilla, C. \& Gill, G. (2003). Effects of crop and weed densities on the interactions between barley and Lolium rigidum in several Mediterranean locations. Agronomie 23, 529-536.

Izquierdo, J., Bastida, F., Lezaun, J. M., Sánchez Del Arco, M. J. \& GonZAlez-AnduJAR, J. L. (2013). Development and evaluation of a model for predicting Lolium rigidum emergence in winter cereal crops in the Mediterranean area. Weed Research 53, 269-278.

Kirkby, K. A., Pratley, J. E., Hume, D. E., Faville, M. J., An, M. \& Wu, H. (2011). Incidence of endophyte Neotyphodium occultans in Lolium rigidum from Australia. Weed Research 51, 261-272.

Kriticos, D. J., Watt, M.S., Potter, K. J. B., Manning, L. K., Alexander, N. S. \& Tallent-Halsell, N. (2010). Managing invasive weeds under climate change: considering the current and potential future distribution of Buddleja davidii. Weed Research 51, 85-96.

Kriticos, D. J., Webber, B. L., Leriche, A., OtA, N., MacAdam, I., Bathols, J. \& Scott, J. K. (2012). CliMond: global high-resolution historical and future scenario climate surfaces for bioclimatic modelling. Methods in Ecology and Evolution 3, 53-64.

Lemerle, D., Verbeek, B. \& CoOmbes, N. (1995). Losses in grain yield of winter crops from Lolium rigidum competition depend on crop species, cultivar and season. Weed Research 35, 503-509.

McConnachie, A.J., Strathie, L. W., Mersie, W., Gebrehiwot, L., Zewdie, K., Abdurehim, A., Abrha, B., Araya, T., Asaregew, F., Assefa, F., Gebre-Tsadik, R., Nigatu, L., TAdesse, B. \& Tana, T. (2011). Current and potential geographical distribution of the invasive plant Parthenium hysterophorus (Asteraceae) in eastern and southern Africa. Weed Research 51, 71-84.

Michael, P. J., Owen, M. J. \& Powles, S. B. (2010). Herbicideresistant weed seeds contaminate grain sown in the western Australian grain belt. Weed Science 58, 466-472.

Missouri Botanical Garden (2014). Tropicos. St. Louis, MO, USA: Missouri Botanical Garden. URL http://www.tropiCOS.org

MONAGHAN, N. M. (1980). The biology and control of Lolium rigidum as a weed of wheat. Weed Research 20, 117-121.

NASS-USDA (2014). Census of Agriculture. Washington, D.C.: USDA. Available online from: www.agcensus.usda.gov (accessed 23 June 2015).

Nı, W. L., LI, Z.H., Chen, H.J., Wan, F.H., Qu, W.W., ZHANG, Z. \& KRITICOS, D.J. (2012). Including climate change in pest risk assessment: the peach fruit fly, Bactrocera zonata (Diptera: Tephritidae). Bulletin of Entomological Research 102, 173-183.

Owen, M. J., Martinez, N. J. \& Powles, S. B. (2014). Multiple herbicide-resistant Lolium rigidum (annual ryegrass) now dominates across the Western Australian grain belt. Weed Research 54, 314-324.

Perarnaud, V., Seguin, B., Malezieux, E., Deque, M. \& Loustau, D. (2005). Agrometeorological research and applications needed to prepare agriculture and forestry to 21 st century climate change. Climatic Change 70, 319-340.

Rahmstorf, S., Cazenave, A., Church, J.A., Hansen, J.E., Keeling, R. F., Parker, D. E. \& Somerville, R. C. J. (2007). Recent climate observations compared to projections. Science 316, 709.

Recasens, J., Taberner, A. \& Izquierdo, J. (1997). Lolium rigidum Gaud. en cultivos de cereales. In Biología de las Malas Hierbas de España (Eds F.X. Sans \& C. Fernández-Quintanilla), pp. 49-64. Valencia, Spain: Phytoma-España.

Steadman, K. J., Ellery, A. J., Chapman, R., Moore, A. \& TURNER, N. C. (2004). Maturation temperature and rainfall influence seed dormancy characteristics of annual 
ryegrass (Lolium rigidum). Australian Journal of Agricultural Research 55, 1047-1057.

Sutherst, R. W. \& MAYWALD, G. (2005). A climate model of the red imported fire ant, Solenopsis invicta Buren (Hymenoptera: Formicidae): implications for invasion of new regions, particularly Oceania. Environmental Entomology 34, 317-335.

Sutherst, R. W., Maywald, G. F. \& Kriticos, D. J. (2007). CLIMEX Version 3: User's Guide. Melbourne, Australia: Hearne Scientific Software.

TABerner, A. (2001). Biología de Lolium rigidum Gaud. Como Planta Infestante del Cultivo de Cebada. Aplicación al Establecimiento de Métodos de Control. Ph.D. Thesis, University of Lleida, Lleida, Spain.

Terrell, E. E. (1968). A Taxonomic Revision of the Genus Lolium. United States Department of Agriculture Technical Bulletin 1392. Washington, D.C.: USDA.
Tutin, T. G., Herwood, V. H., Burges, N. A., Moore, D. M., Valentine, D. H., Walters, S. M. \& WebB, D. A. (1980). Flora Europaea. Vol. 5, Alismataceae to Orchidaceae (Monocotyledones). Cambridge, UK: Cambridge University Press.

USDA (2014). The PLANTS Database. Washington, DC: USDA. Available online from: http://plants.usda.gov (accessed 23 June 2015).

Walck, J. L., Hidayati, S. N., Dixon, K. W., Thompson, K. \& Poschlod, P. (2011). Climate change and plant regeneration from seed. Global Change Biology 17, 2145-2161.

Ziska, L. H., Blumenthal, D. M., Runion, G. B., Hunt, E. R. \& Diaz-Soltero, H. (2011). Invasive species and climate change: and agronomic perspective. Climate Change 105, 13-42. 